\title{
Analysis on the influence of sinusoidal wind on the structure of pumping unit based on dynamics of solid-fluid interaction
}

China National Petroleum Corporation Dingbian oilfield is located in the wind field area of the beam pumping unit affected by the wind load, occurred several pumping unit bracket bending, beam fracturing, horsehead off and horsehead drop and other serious accidents, endanger the equipment and personnel safety. However, there is little research on the influence of beam pumping unit under wind load. Based on the dynamics of solid-fluid interaction theory and the standard $k-\varepsilon$ turbulence model, this paper calculated the polished rod load range of the pumping unit according to the actual working condition of Dingbian oilfield, and established the CYJ10-4.2-53 numerical model of wind field. Under the sinusoidal variable wind speed conditions, the stress and deformation of the beam loader with different sizes of wind load on the beam loader were compared to those of the different sorts. The stress and deformation of the two different types of pumping unit were compared under the wind load. The results show that under the influence of wind load, the rig of the pumping unit bracket has a serious bending deformation, and the safety risk of the front end of the horsehead along the wind load is deformed. When the wind speed reaches $24.48 \mathrm{~m} / \mathrm{s}$, the horsehead and barcket's offset is the largest to the top dead point by the wind load, The minimum impact is affected by the wind load at the bottom dead center, The maximum offset of the horsehead and the bracket reached $8.5 \mathrm{~mm}$ and 2.16 $\mathrm{mm}$. The research work of this paper provides a scientific basis for the improvement of safety structure for pumping unit in the wind field area.

Keywords: Wind load, beam pumping unit, dynamics of solid-fluid interaction, hidden danger

\subsection{Introduction}

B eam pumping unit is widely used in oil extraction equipment at home and abroad, its working principle can be defined as Crank rocker mechanism movement, which is the retarder turns crank rotation, and crank rotation

Messrs. Zheng Liang, Luo-ming Zhao, School of Mechanical Engineering, Southwest Peroleum University, Chengdu, Key Laboratory of Oil and Gas Equipment, Ministry of Education, Chengdu and Li-qin Tan, CNPC Baoji Oilfield Machinery Co., Ltd, Baoji, China. drives beam swing to achieve the reciprocating movement of the sucker rod, and then drives to pump oil.

At present, the research on beam pumping unit mainly focuses on reducing the energy consumption of pumping unit and improving the oil extraction efficiency of pumping unit. For example, Yongjun Hou et al. proposed a new type of beam pumping unit balance device combined with mechanical and electrical systems (Hou and Zhang, 2014). This device reduced the energy consumption of the beam pumping unit and improved the security. Anyi Huang et al.used the MATLAB software to establish the computer emulation model of the crank balance beam pumping system (Huang and Li, 2010). Liang Gao et al. combined with mechanical and electrical system, proposed a pumping unit balance adjustment device to improve the balance efficiency and security of pumping unit (Gao, Cui, Bai and Liu, 2017). Futian $\mathrm{Li}$,et al. carried out dynamic stress test on the horsehead, analyzed the crack of pumping unit horsehead, and put forward the improvement measures ( $\mathrm{Li}$, Zhang and $\mathrm{Xu}$, et al. 2014). Guochen Shi et al. analyzed the influence of inertial load to dynamic characteristic of beam pumping units when the pumping units ran at variable speed (Shi, Feng and Zhang, et al. 2015). Xiangyu Li et al. established a coupled dynamic model for polished rod load of beam pumping unit, which can be used to predict the condition parameters and detect faults of pumping unit load and pump efficiency (Li, Gao and Hou et al. 2016). Aliev. T.A et al, aiming at the operation of the pumping unit, proposed an algorithm for automatic identifying hitch of pumping unit (Aliev, et al. 2015).

Recently, the impact of wind load on the safety of the pumping unit was not considered in the research on the pumping unit. In our country, Xinjiang, Gansu, Inner Mongolia and other regions, due to the larger wind speed, especially many large oil equipment such as pumping units, rigs and workover rig derricks located in the wind field were damaged by the windstorm disaster. Pumping units under the action of the wind load would cause the bracket bending, and the deviation of sucker rod exacerbated a series of safety risks such as the wear of wellhead blowout preventor. Fig. 1 is the photo of beam pumping unit located in China National Petroleum Corporation Dingbian oilfield damaged by wind, it 


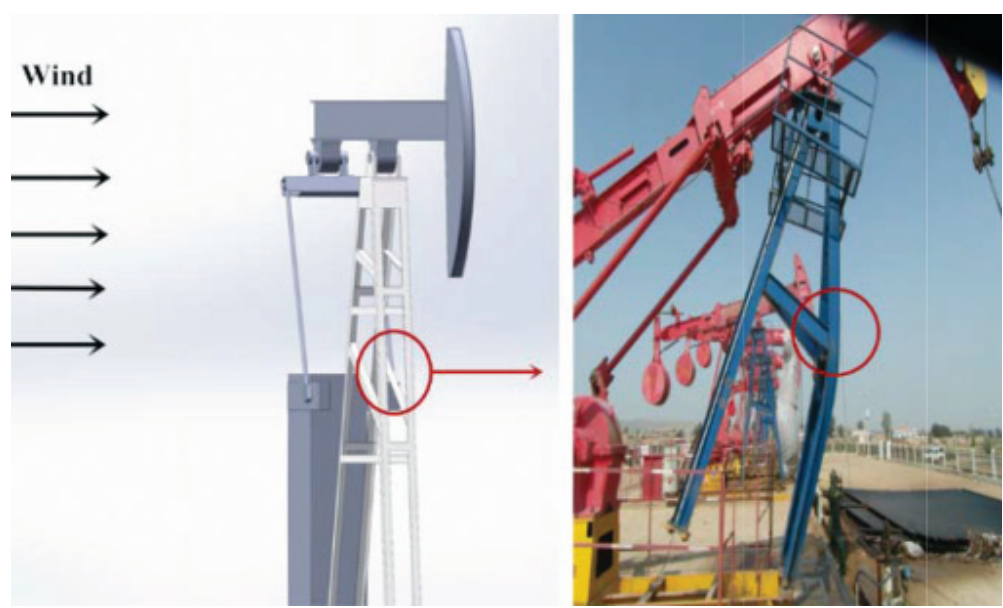

Fig.1 Pumping unit is damaged by wind the pump unit was less affected by the wind load when the position of retarder and the base was low. Therefore, the retarder and the base was simplified as a whole, and in the process of modelling, the design standard of the pumping unit was strictly used (Shi and Xiao, 2004), in which the beam adopted the steel-shaped beam, and the horsehead was made of a bar head. Fig. 2 showed the establishing of pumping unit model diagram in 3D modelling software. The material of pumping unit was Q235, material properties was shown in Table 2. In the analysis, it was assumed that the fluid was a viscous incompressible fluid, and the influence of fluid gravity was neglected. It could build the boundary as follow: the fluid inlet was $5 \mathrm{~m}$ from the pumping unit and the exit boundary was $8 \mathrm{~m}$ from showed the bracket of pumping unit has been seriously bent and out of the base, and it could not work properly.

In this paper, the full-scale fluid-solid coupling dynamics model of CYJ10-4.2-53 pumping unit was established, fluid dynamics software Fluent was carried out to calculate the sinusoidal variable wind speed and the transient structural module in ANSYS software for transient dynamics analysis was used in structural response calculation of pumping uniteach physical time step to do the coupling iteration, and calculated the parameters change of pumping unit in different wind speed, deformation under different motion conditions, stress and other conditions.

\subsection{Numerical simulation method}

\subsection{GEOMETRIC MODEL AND GRID PARTITION}

Pumping unit integral structure size was shown in Table 1, when the model of the pumping unit was established, the model should be simplified and some small features would be removed, such as chamfer, holes, solder joints, etc. Because
TABle 1: Pumping Unit InTEgRal STRUCture SIZE

\begin{tabular}{ll}
\hline Type & CYJ10-4.2-53 \\
\hline Rated polished rod load $(\mathrm{KN})$ & 100 \\
Polished rod stroke length $(\mathrm{m})$ & 4.23 .63 \\
Jig frequency (min-1) & 1086 \\
Reducer rated torque (KN.m) & 53 \\
Dimensions length $\times$ width $\times$ height $(\mathrm{mm})$ & $11250 \times 2280 \times 8420$ \\
\hline
\end{tabular}

TABle 2: Pumping unit Material Properties

\begin{tabular}{llll} 
Material & Density $\left(\mathrm{kg} / \mathrm{m}^{3}\right)$ & Poisson's ratio & $\begin{array}{l}\text { Young's modulus } \\
\left(\mathrm{N} / \mathrm{m}^{2}\right)\end{array}$ \\
\hline Q235 & $7.83 \mathrm{E}+03$ & 0.274 & $2.10 \mathrm{E}+11$ \\
\hline
\end{tabular}

the pumping unit and with radius $10.8 \mathrm{~m}$ of cylindrical inward flow field inclusions model. The external flow grid division was adopted the hexahedral mesh method and then generated hexahedral mesh, including 155,940 nodes and 209,278 units. The pumping unit grid model diagram was shown in Fig.2.
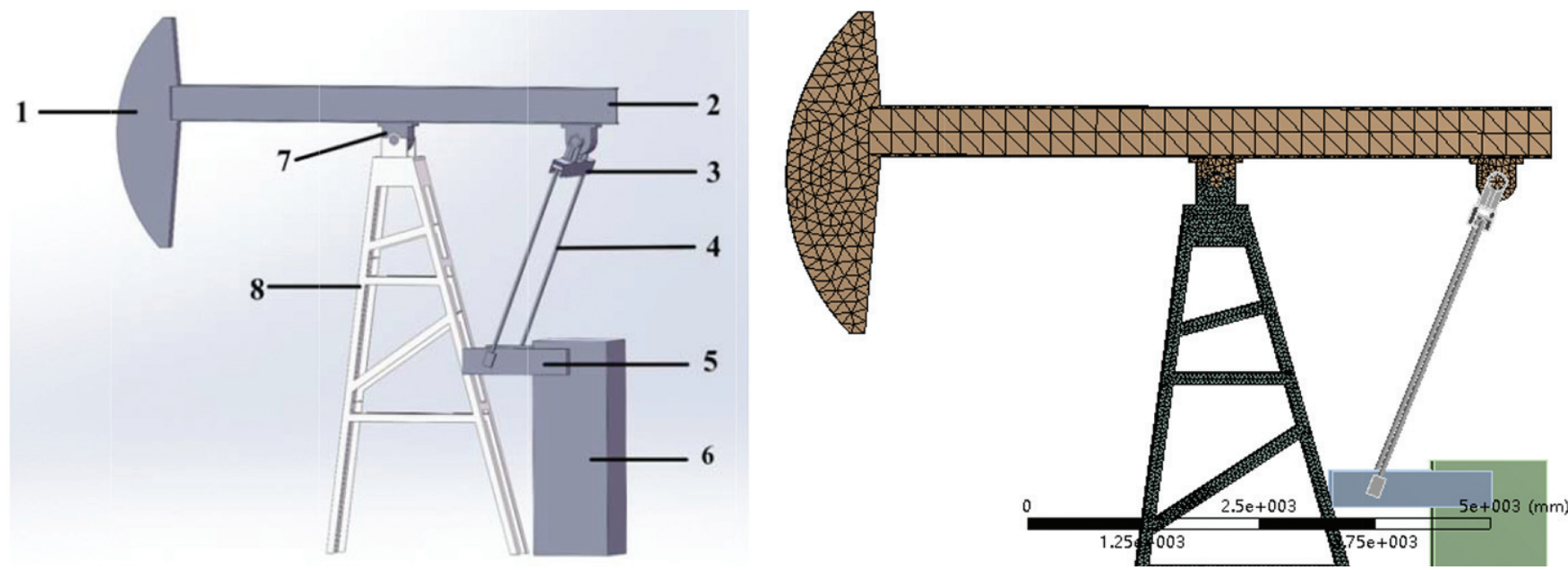

1- horsehead; 2-beam; 3- crossbeam; 4- connecting rod; 5- crank; 6- pedestal; 7- the central bearing seat; 8- bracket

Fig.2: Pumping unit model and grid model diagram 


\subsection{CAlculation of POlished ROD LOAD AND BOUNDARY} CONDITION

\subsubsection{Calculation of polished rod load}

Polished rod load is an important parameter in the design of the pumping unit, because in the process of extracting oil, when the pumping unit moves to a different position, the horsehead is subjected to constant polished rod load from the horsehead and the sucker rod. Therefore, the influence of the polished rod load on the pumping unit can not be neglected when the actual working conditions of the pumping unit are analyzed. And when the load of the pumping unit is calculated, the law of the movement of the pumping unit should be simplified as simple harmonic motion. When the pumping unit is the largest, the minimum polished rod load formula is

$$
\begin{aligned}
& P_{\max }=\left(P_{p}+P_{\text {oil }}^{\prime}\right)\left(1+\frac{s n^{2}}{1790}\right) \\
& P_{\min }=P_{p}\left(1-\frac{s n^{2}}{1790}\right) \\
& P_{p}=\rho_{p} g f_{p} L \\
& P_{\text {oil }}^{\prime}=F\left(L-h_{s}\right) \rho_{\text {oil }}
\end{aligned}
$$

The basic parameters of beam pumping unit, sucker rod and oil well pump are shown in Table 3. Plug successively parameters form Table 3 into equation (3), (4), figure out the weight of sucker $\operatorname{rod} \operatorname{prod} P_{p}$, and oil column weight $P_{\text {oil }}$, then, plug $P_{p}$ and $P_{\text {oil }}$ into the equation (1), (2), and calculate maximum suspension point load $P_{\text {max }}=68928 \mathrm{~N}$, the minimum suspension load is $P_{\min }=31426 \mathrm{~N}$. The maximum suspension point load is $100 \mathrm{KN}$ smaller than rated suspension load of pumping unit, which conforms to the design specification for pumping units.

\subsubsection{Boundary conditions}

Using the $k-\varepsilon$ model of the turbulence model, the wall was set to the wall slip boundary and used the velocity-inlet and pressure-outlet boundary condition. The pressure velocity coupling adopted a SIMPLE algorithm, and the influence of gravity on the flow field is neglected. Considering that the wind speed in the wind field was constantly changing, and consulting the simulation model of fluctuating wind field, the wind speed change at the inlet of the external flow field was simulated as a sinusoidal change, and the speed is expressed as

$$
U_{(t)}=U_{0}+U_{0} R \sin \omega t=U_{0}(1+R \sin (2 \pi f t))
$$

In the equation, $U_{0}$ was the average wind speed, $R(R<1)$ was the dimensionless amplitude, and $f$ was the wind speed pulsation frequency.

The general data of the wind speed in the wind field was obtained by taking the average of the measured data. Taken $U_{0}$ was equal to $16 \mathrm{~m} / \mathrm{s}, R$ was equal to 0.53 corresponding speed range of $7.52 \sim 24.48 \mathrm{~m} / \mathrm{s}, f$ was equal to $0.125 \mathrm{~Hz}$, for the formula (5) to write the speed of the entrance UDF programme, the calculation of the number of steps was 800 steps and the time step was $0.01 \mathrm{~s}$.

The boundary condition of the solid domain was to set the pumping unit bracket and the bottom of retarder as a fixed constraint, and the motion of the polished rod load was simplified as a simple harmonic motion. The polished rod load applied on the upper part of the horsehead and direction of force tangent downward to the front face of horsehead, when the maximum and minimum polished rod loads were respectively at the top dead center and the bottom dead center, the motion cycle of pumping unit was $10 \mathrm{~s}$ and the wind load was divided into different stages on the pumping unit and the side of the horsehead, as shown in Fig.3.

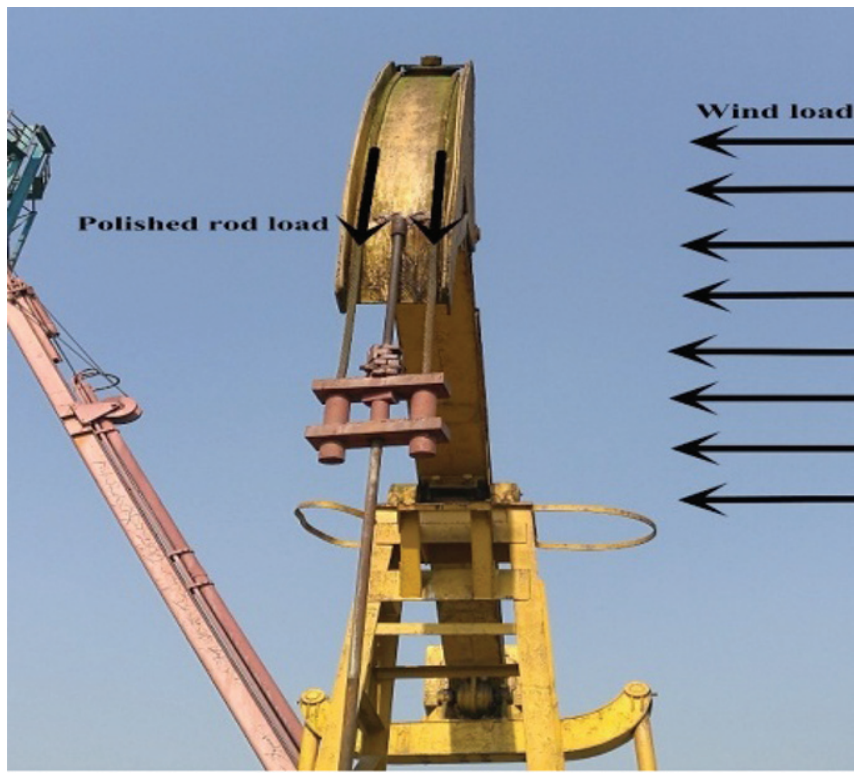

Fig.3: Pumping solid boundary conditions

\subsection{Results and analysis of simulation}

\subsection{ANALYSIS OF FLOW FIELD NEPHOGRAM}

When the side of the wind load applied to the surface of the pumping unit, the wind area was the largest, the impact

TABLE 3: BASIC PARAMETERS OF THE BEAM PUMPING UNIT

\begin{tabular}{ccccccc}
\hline $\begin{array}{c}\text { Rated polished } \\
\text { rod load(KN) }\end{array}$ & $\begin{array}{c}\text { stroke of } \\
\text { polished } \\
\text { rod(m) }\end{array}$ & $\begin{array}{c}\text { jig frequency } \\
(\text { min-1) }\end{array}$ & $\begin{array}{c}\text { Rod nominal } \\
\text { diameter } \\
(\mathrm{mm})\end{array}$ & $\begin{array}{c}\text { pump size } \\
(\mathrm{mm})\end{array}$ & $\begin{array}{c}\text { pump } \\
\text { depth(m) }\end{array}$ & $\begin{array}{c}\text { submergence } \\
\text { depth of the } \\
\text { pump }(\mathrm{m})\end{array}$ \\
\hline 100 & 4.2 & 6 & 22 & 70 & 1150 \\
\hline
\end{tabular}


of wind load on the pumping unit was also the greatest. Therefore, the lateral wind load under the change of sinusoidal wind speed was calculated and analyzed when the pumping unit was in different positions. Fig.4 was wind field pumping flow diagram and the Fig.5 was under different wind velocity of the flow field stress nephogram.

It can be seen from Figs. 4 and 5 that the wind load could affect the windward side of the pumping unit and also resulted in the flow around on the back of pumping unit. When the wind speed $v=24.48 \mathrm{~m} / \mathrm{s}$, the surface pressure on the structure parts of pumping unit was the largest, the surface pressure on the beam and horsehead was larger than the surface pressure on the bracket, and the surface pressure increased from outside to inside. With the decrease of wind speed, the surface pressure on the pumping unit was gradually reduced, when the wind speed $\mathrm{v}=7.52 \mathrm{~m} / \mathrm{s}$, the surface pressure got to a minimal.

\subsection{INFLUENCE OF DIFFERENT PARAMETERS ON PUMPING UNIT}

\subsubsection{The change in wind speed}

Figs. 7 and 10 showed the calculation results of the hydrodynamic coupling under different wind speeds when the pumping head was applied to the top dead center.

Fig.7 showed the offset displacement curve of the beam and the horsehead at different wind speeds when the horsehead moved to the top dead center. Combined with the Fig.6, when the wind speed $v=0 \mathrm{~m} /$ $\mathrm{s}$, the beam was only affected by the polished rod load, the offset displacement of the beam was very small, at this time the maximum offset displacement was only $0.053 \mathrm{~mm}$. With the increase of lateral wind speed, the offset displacement of the beam increased, and when the wind speed was $\mathrm{V}$ $=24.48 \mathrm{~m} / \mathrm{s}$, the offset displacement of the beam reached the value of $8.5 \mathrm{~mm}$.

Fig.10 was the offset displacement and equivalent stress curve of bracket of pumping unit in different wind speed when the horsehead move to the top dead center. From Fig. 8 and Fig.9 could be seen: when the wind speed $v=0 \mathrm{~m} / \mathrm{s}$, the maximum offset displacement of the bracket was $0.23747 \mathrm{~mm}$, and the maximum offset occurred in the upper part of the bracket. With the increasing of wind speed, the offset displacement of the bracket increased, the maximum offset displacement was $2.16 \mathrm{~mm}$. Because the wind area of the bracket was small, the change of the equivalent stress of the bracket was not

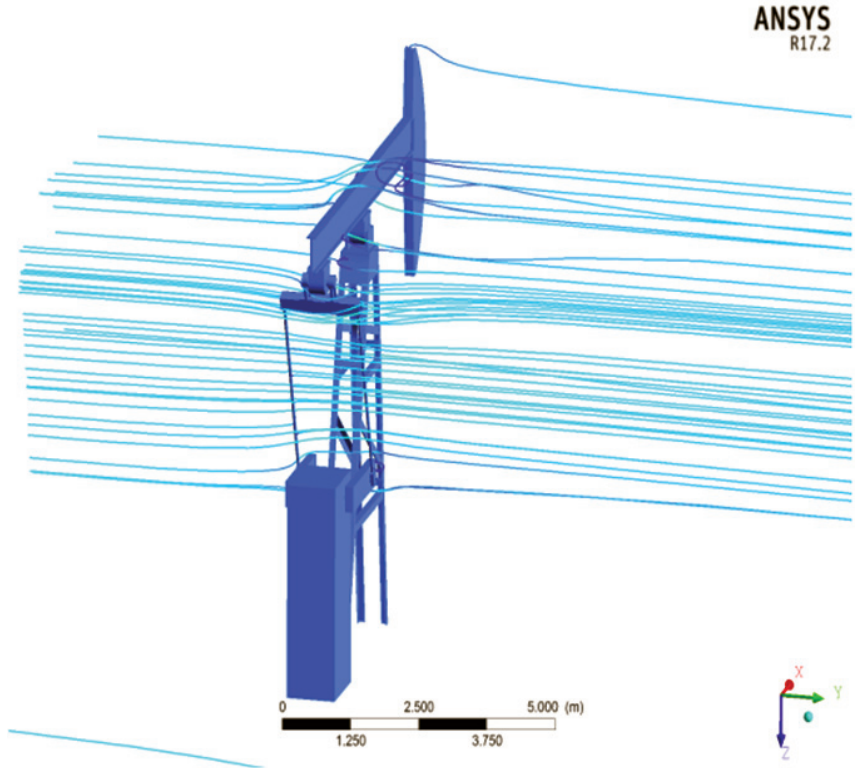

Fig.4 Wind field pumping flow diagram
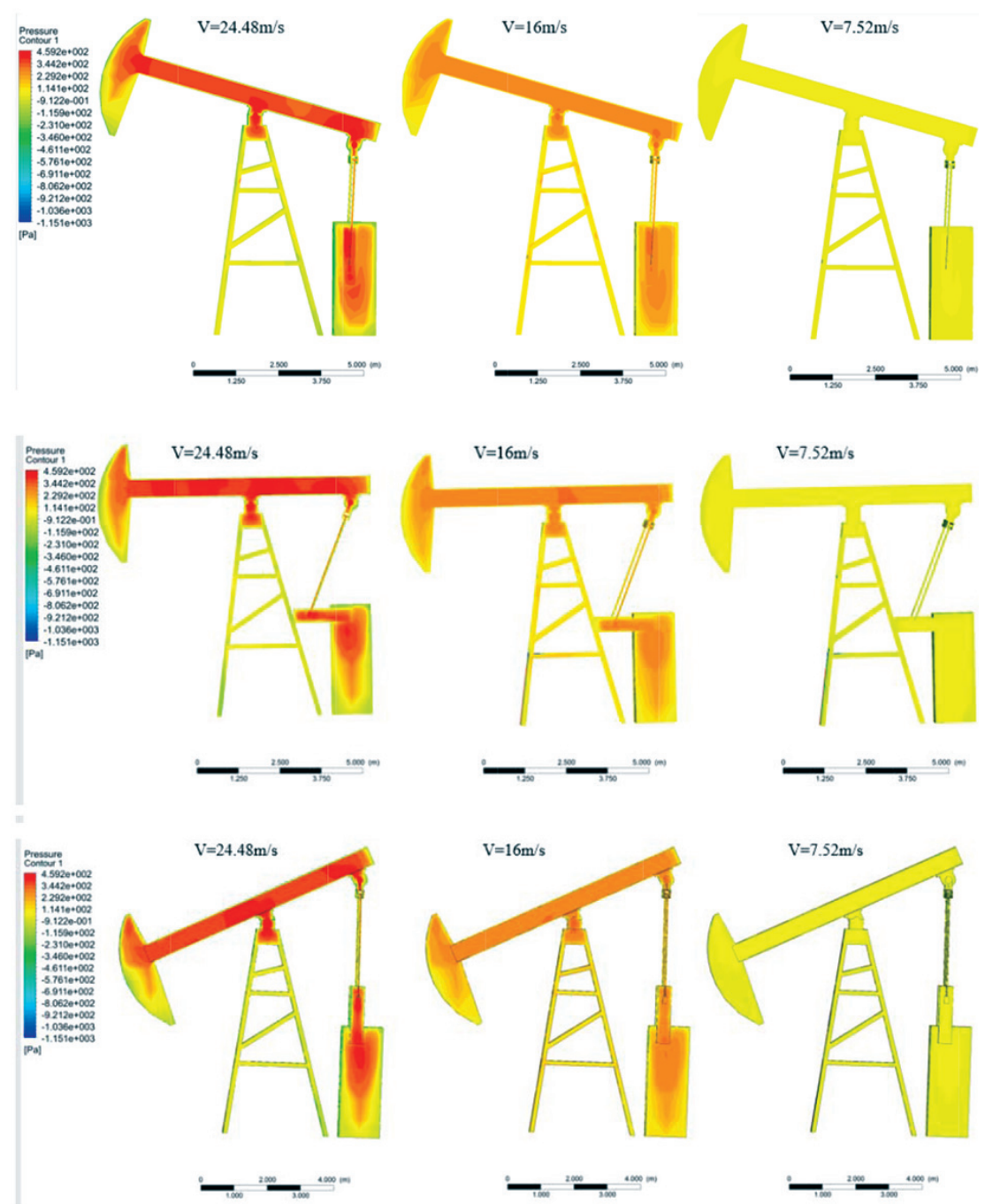

Fig.5: The flow field stress nephogram under different wind velocity 


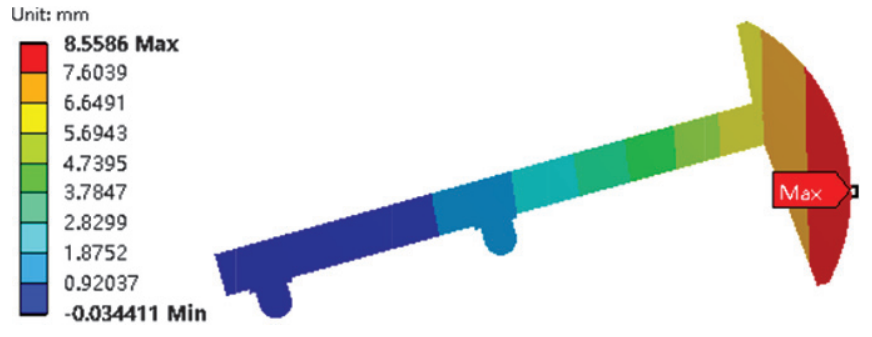

Fig.6: The wind speed $v=24.48 \mathrm{~m} / \mathrm{s}$ beam deformation nephogram

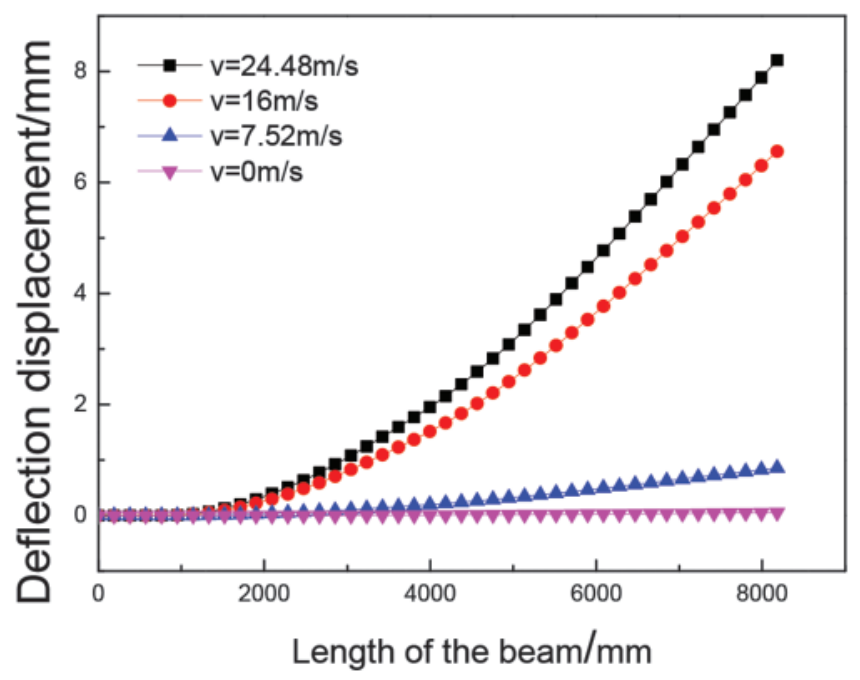

Fig.7: The displacement of beam deflection curve
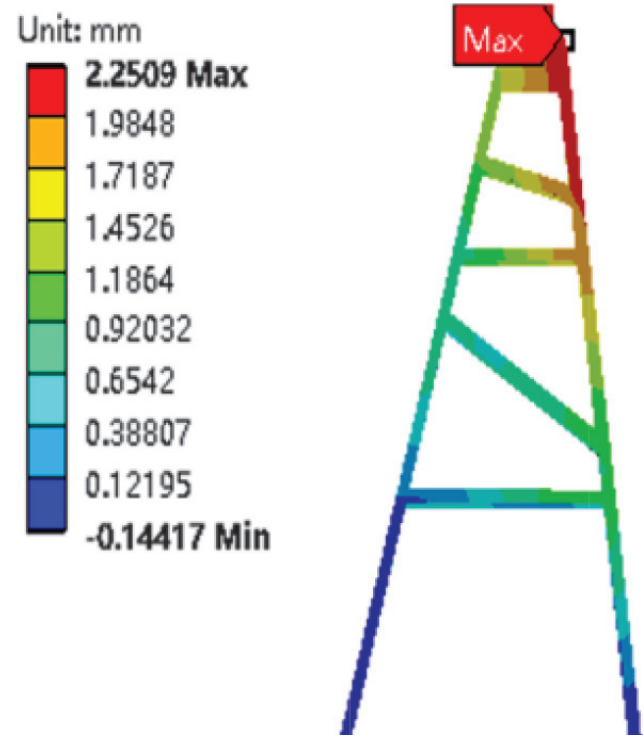

Fig.8: The wind speed $v=24.48 \mathrm{~m} / \mathrm{s}$ bracket deformation nephogram

obvious at different wind speed. This illustrated that the wind load on the beam and donkey head of the impact could not be ignored.

Fig. 11 was the bracket deformation nephogram contrast
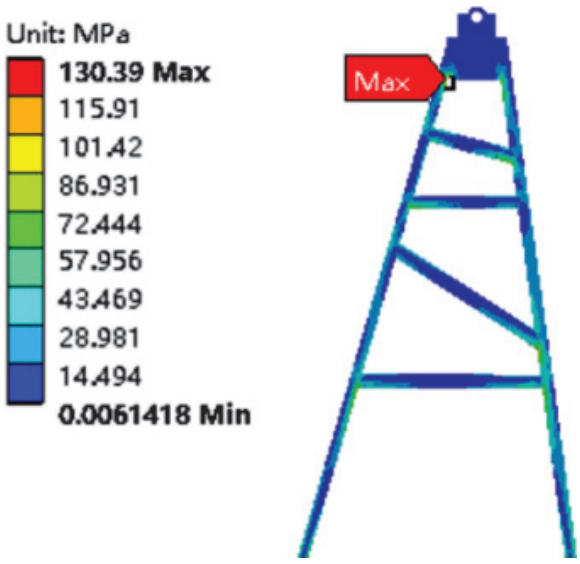

Fig.9: The wind velocity $v=24.48 \mathrm{~m} / \mathrm{s}$ bracket equivalent stress nephogram
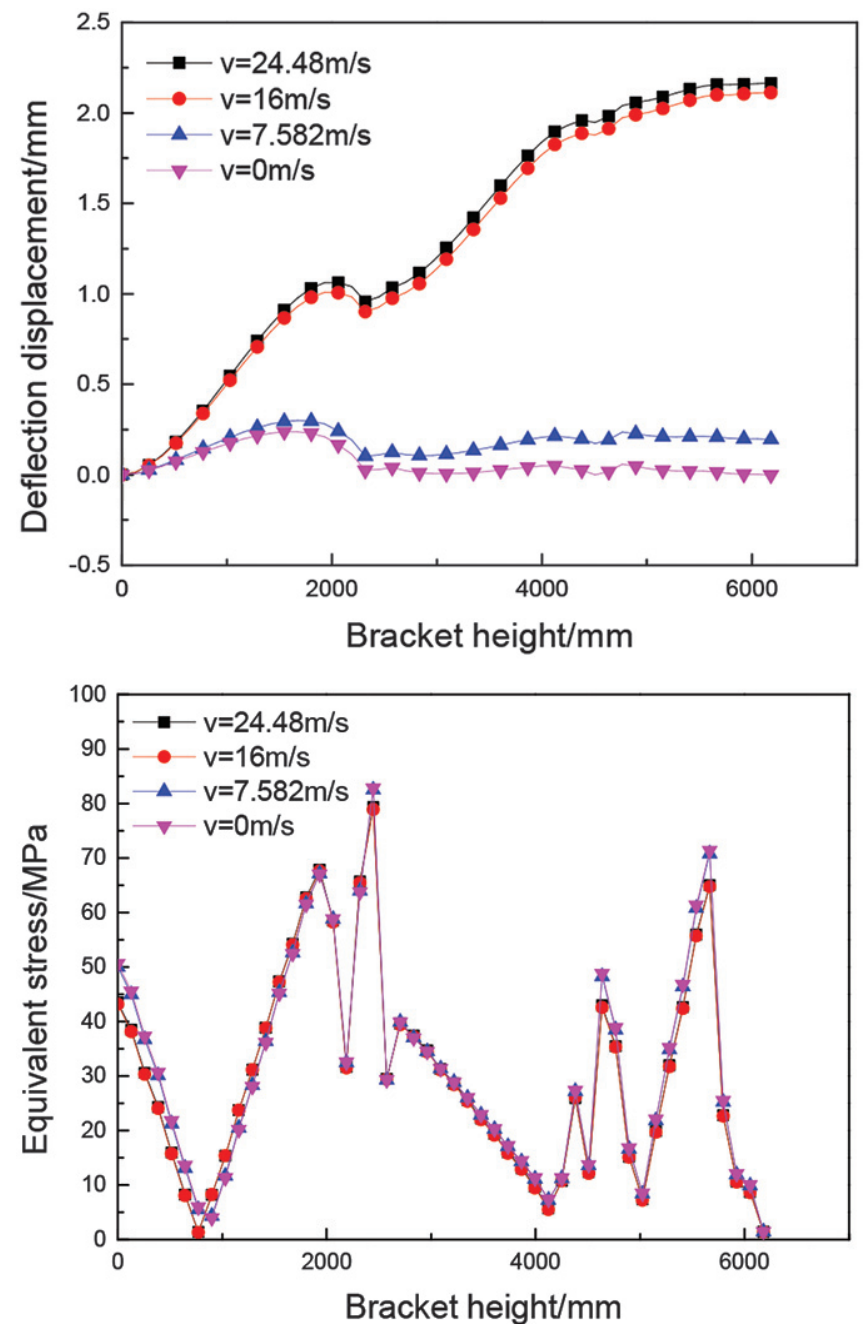

Fig.10: The bracket height of the offset displacement and equivalent stress curve

figure with the accident. It could be seen that under the influence of wind load, the bracket had obvious inward bending deformation, and seriously affected the safety of the pumping unit, which consisted with the maximum position on 


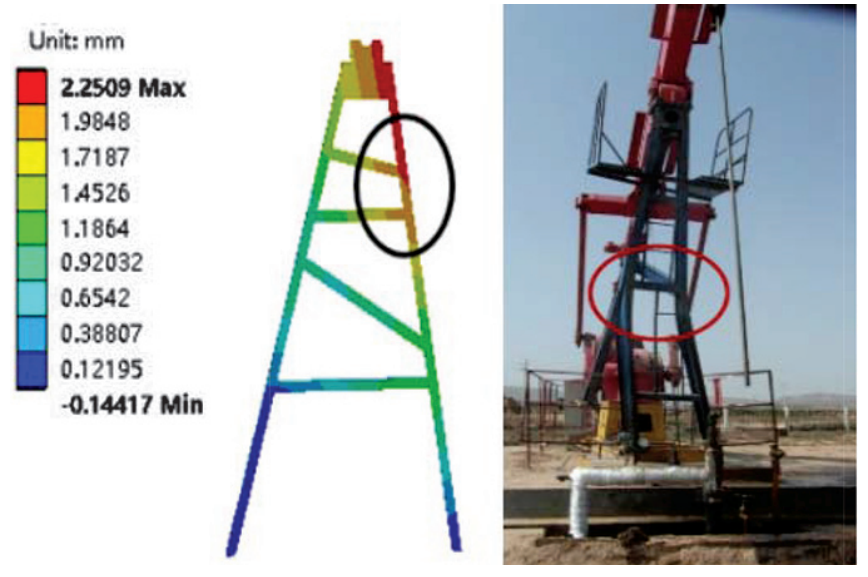

Fig.11: Bracket deformation nephogram contrast figure with the accident

the cloud map near the junction of the support beam and verified the correctness of the simulation results.

\subsubsection{The change of polished rod load}

For the same wind speed $(v=24.48 \mathrm{~m} / \mathrm{s})$, the calculation results of the fluid-solid coupling under varying polished rod load were shown in Figs.12 and 14. Fig.12 showed that polished rod load was different, when the horsehead worked in different positions. When the horsehead got to the bottom dead center, the polished rod load got the maximum, when the horsehead moved to the top dead center, the polished rod load was the minimum. In the case of extreme windy weather, in order to ensure the the safety of the pumping unit, safety measures could be taken to stop the pumping unit. And considering the big influence of wind load on the pumping unit bracket and taking the bracket as an example, the deformation and equivalent stress comparison of the horsehead under no polished rod load in different positions was analyzed when the punping unit stopped. The calculation results were shown in Figs.12 and 15.

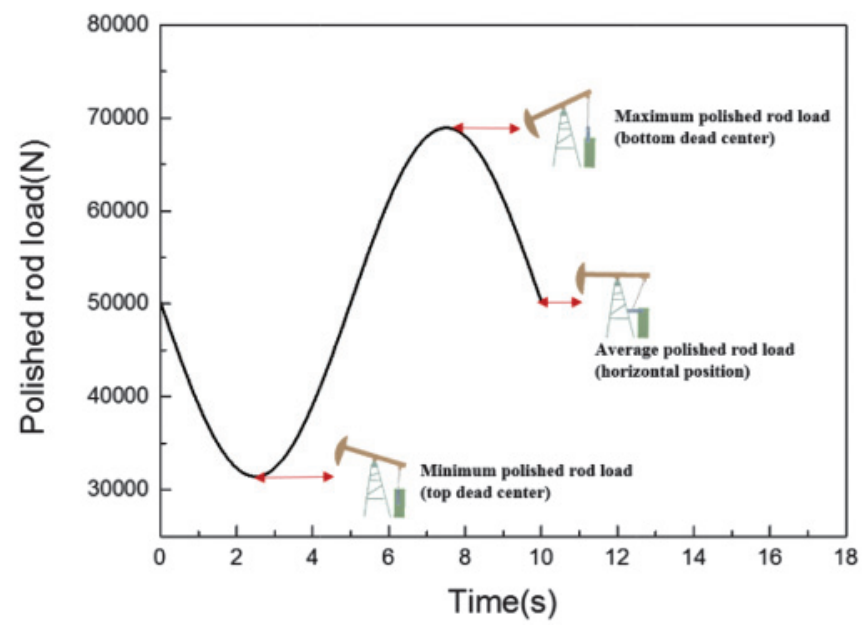

Fig.12: The curves of polished rod load

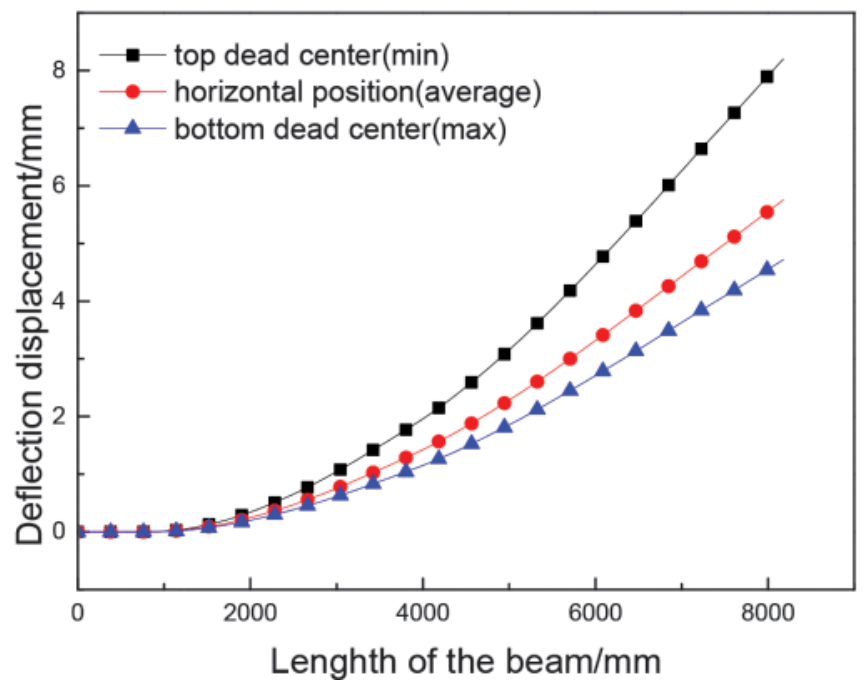

Fig.13: Beam deflection displacement under different polished rod load
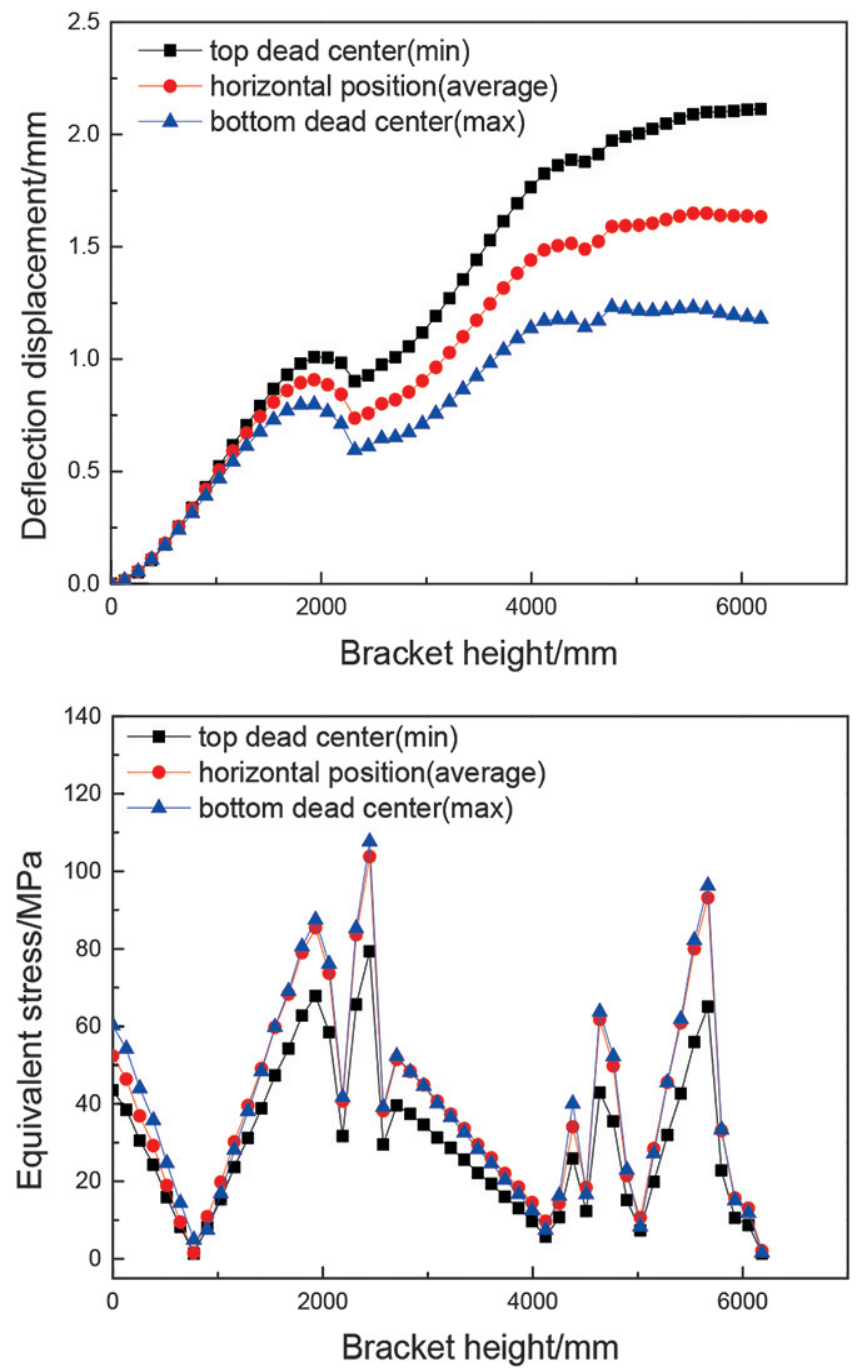

Fig.14: Bracket migration displacement and equivalent stress under different polished rod load 

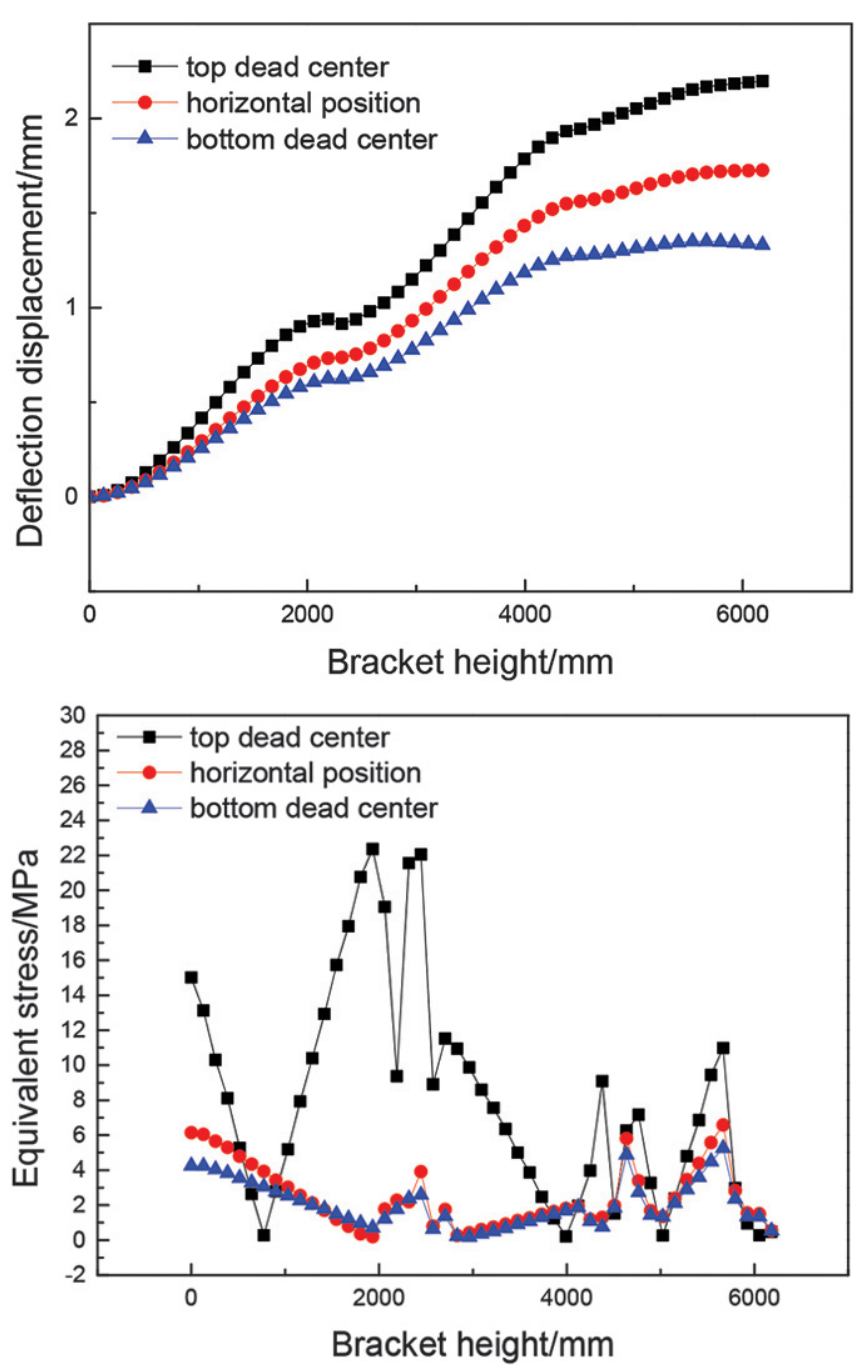

Fig.15: The donkey head in different position of stent deformation and equivalent stress under no polished rod load

Fig.14 showed the deflection displacement under different polished rod load of the beam when the wind speed was equal to $24.48 \mathrm{~m} / \mathrm{s}$. It could be seen that when the horsehead moved to the bottom dead center, the maximum offset displacement occurred in the front of the horsehead, the maximum offset displacement was $4.72 \mathrm{~mm}$. Due to the influence of wind load on the structure was related to the height of the structure, when the horsehead movement to the top dead center was higher than the height of horsehead movement to the bottom dead center, the deflection displacement of horsehead at the top dead center was the largest.

Fig.15 showed the deflection displacement under different polished rod load of the pumping unit bracket when the wind speed was equal to $24.48 \mathrm{~m} / \mathrm{s}$. It could be seen that when the horsehead moved to the bottom dead center, the maximum offset displacement of bracket was $1.2292 \mathrm{~mm}$. the maximum offset displacement occurred on the upper part of the bracket. The maximum stress was $107.67 \mathrm{MPa}$, and the maximum stress was concentrated on the upper part of the bracket. When the horsehead moved to the top dead center, the maximum offset displacement was $2.1128 \mathrm{~mm}$, the maximum equivalent stress was $79.33 \mathrm{MPa}$. The difference between the maximum equivalent stress at the top dead center and the bottom dead center of the donkey reached 28.34 $\mathrm{MPa}$, but the difference in the maximum offset displacement was only $0.8836 \mathrm{~mm}$, which was almost negligible. This explained that when the pumping unit is operating within the effective polished rod load range, the impact on the horsehead by the wind load was the greatest when moving upward, and even certified the correctness of the simulation calculation. The deformation and equivalent stress, when CYJ10-4.2-53 type pumping unit worked on the bottom dead center, was less than it worked on the top dead center. It indicated that in the extreme windy weather, the safety measure of pumping keeping in operation to the bottom dead center should be taken.

\subsubsection{COMPARISON OF BRACKEY STRUCTURE OF PUMPING UNIT}

The bracket structure of pumping unit was divided into with brace of bracket and without brace of bracket. Fig. 16 was the comparison of the beam pumping unit of two different brackets. Using comparative analysis, when the horsehead of pumping unit moved to the top dead center, the result of the two brackets in the same wind speed was shown in Fig.17.

Fig. 17 was the comparison curve of the equivalent stress of the offset displacement of the with and without brace of pumping unit bracket when the wind speed was equal to 24.48 $\mathrm{m} / \mathrm{s}$ and the horsehead worked to the top dead center. As could be seen, the maximum offset displacement of the brace bracket was $0.08 \mathrm{~mm}$ smaller than without brace of the bracket, and the maximum equivalent stress of the brace brackets was $43.23 \mathrm{MPa}$ smaller than without brace of the

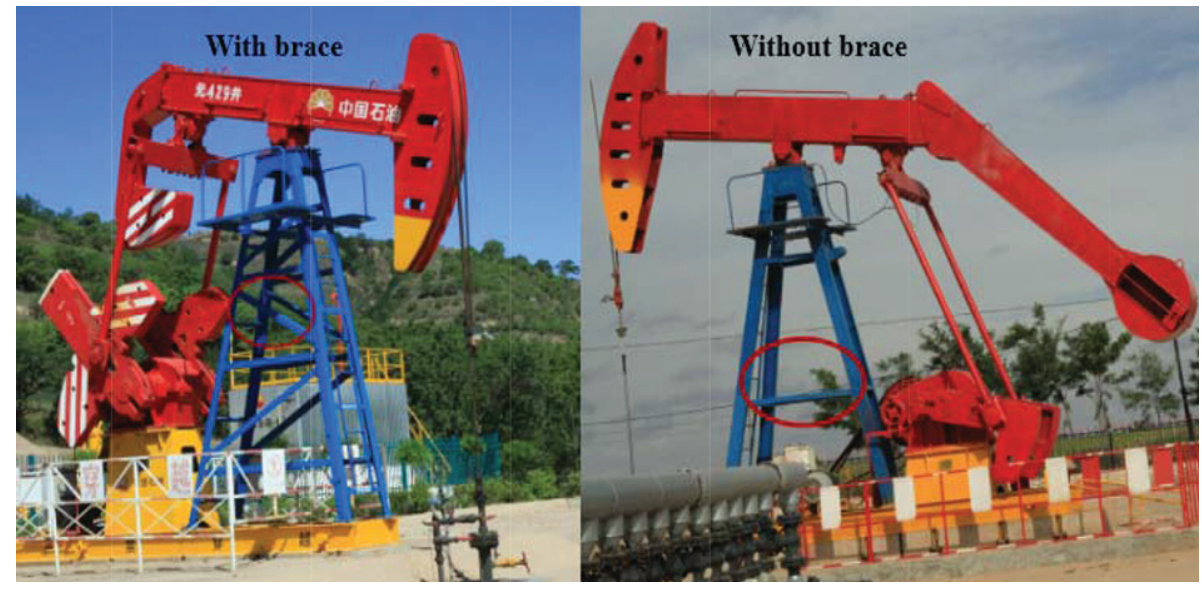

Fig.16: With and without brace of pumping unit bracket 

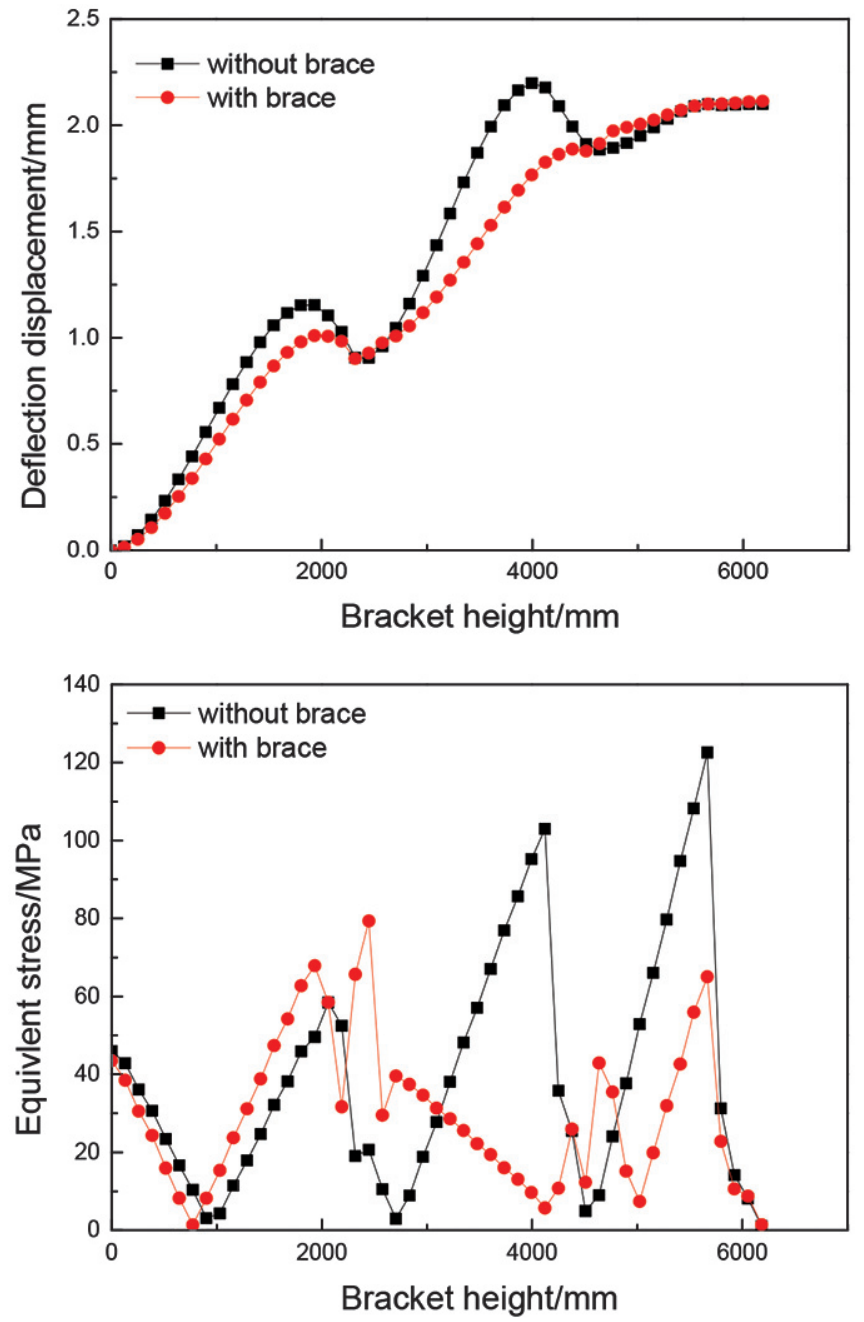

Fig.17: Different bracket migration displacement and equivalent stress

bracket. This showed that the braces are safer than those without braces. With the influence of wind load, a brace bracket should be adopted to reduce the effect of wind load of pumping unit.

\subsection{Conclusions}

In this paper, the model of CYJ10-4.2-53 pumping unit is established, and the dynamics of solid-fluid interaction under sinusoidal variation of wind speed is analyzed. The main conclusions are as follows: Pumping unit affected by the wind load will lead to the bending of bracket and beam and the deviation of horsehead and other security risks. As the surface area is large, the impact on horsehead and beam by the wind load is the greatest. With the increase of wind speed, the displacement of the beam and the bracket increases, and the maximum offset reaches $8.5 \mathrm{~mm}$ and $1.91 \mathrm{~mm}$ respectively when considering the actual wind speed of the Dingbian oilfield. The equivalent stress of the bracket under different wind speed is not changed, but the deformation mainly concentrates on the upper end of the bracket. With the change of the polished rod load, the horsehead moves from bottom to top and the offset displacement of the beam increases, and the equivalent stress is the highest in the horizontal position. The offset displacement of bracket and the law of equivalent stress are consistent with the actual wind field in Dingbian oilfield. In the extreme windy weather, the safety measure of pumping keeping in operation to the bottom dead center should be taken. The bracket design of pumping unit in the wind field should be more secure with a braced bracket. In the process of designing the wind field application of the pumping unit and the safety assessment, the wind load must be considered, otherwise it may lead to lack of safety of pumping unit.

\section{References}

1. Anyi Huang and Hai-liang Li. (2010): Computer emulation and analysis of beam pumping unit system. Journal of Southwest Petroleum University, 3(1), 67-70.

2. Futian Li, Sheng Zhang and Ming Xu, et al. (2014): Stress Test and Crack Analysis of Pumping Unit Horsehead. Oil Field Equipment, 43(80,103-107.

3. Guochen Shi, Ziming Feng and De-shi Zhang, et al. (2015): Influence of Inertial Load to Dynamic Characteristic of Beam Pumping Units. Oil Field Equipment, 44(3), 34-37.

4. Xiangyu Li, Xianwen Gao and Yan-bin Hou et al. (2016): Coupled Dynamic Modelling for Polished Rod Load of Beam Pumping Unit. Journal of Northeastern University, 37(9), 1225-1229.

5. Aliev, T.A., Nustratov, O.G.,Guluyev, G.A.,Rzayev, As.H., Pashayev, F.H, Rezvan, M.H., Kerimov, A.B. (2015). Algorithms for Diagnostics of Fault Conditions of the Sucker Rod Pumping Units. Mekhatronika Avtomatizatsiya Upravlenie, 16(5), 314-320.

6. Zhiwei Shi and Xiao Ming. (2004): The effects of unsteady free stream on aerodynamics of an aircraft model. Acta Aerodynamica Sinica, 22(4), 466-469.

7. Yongjun Hou and Qiang Zhang. (2014): Research of rack pumping unit and finite element analysis of the tower. Journal of Machine Design, 31(10), 81-83.

8. Jie Li and Linlin Zhang (2007): Research on random Fourier spectrum of observational wind. Journal of Vibration Engineering, 20(1), 66-72.

9. Liang Gao, Xin Cui, Ye Bai and Jianxing Liu. (2017): Comparative analysis of three ways uesd to study the characters of strong wind in inland China. Journal of Xi'an University of Technology, 33(1), 41-44. 